\section{COMPARATIVE ENDOCRINOLOGY OF VERTEBRATES}

\begin{abstract}
$\mathrm{N}$ international symposium on the comparative endocrinology of vertebrates was held in the Zoology Department, University of Liverpool, during July 12-16. It was made possible by the generous financial support of the Rockefeller Foundation and the United States National Science Foundation. The Derby professor of zoology, Prof. R. J. Pumphrey, on behalf of the University, officially welcomed the participants, who numbered about seventy-five. The symposium was divided into two parts, the first entitled "The Comparative Physiology of Reproduction" being under the chairmanship of Prof. S. Zuckerman ; for the second part, on "The Hormonal Control of Water and Salt-electrolyte Metabolism in Vertebrates", Dr. S. J. Folley took the chair.

The first two days were devoted to a comparative survey of reproduction, starting with a paper on fish by Prof. W. S. Hoar (Vancouver), who, even though confining his survey to the teleosts, surprised many of his audience with the wide variety of reproductive patterns ranging from oviparity to viviparity met with in the bony fish. In discussion of this paper, Dr. A. S. Parkes raised the interesting question of how the sperm penetrates into the ovarian follicles in those forms in which intrafollicular fertilization occurs. This question could not be answered.

Prof. G. J. van Oordt (Utrecht) dealt with the male amphibian, his paper describing an experimental analysis of seasonal fluctuations in spermatogenesis in frogs which emphasized the part played by variations in sensitivity of the seminiferous tubules to pituitary gonadotrophins. In the discussion, Dr. H. Tuchman-Duplessis referred to experiments on the newt which suggested that eyclic variations in pituitary gonadotrophic activity may be another factor involved in seasonal changes in spermatogenesis in amphibia. Dr. C. L. Smith (Liverpool) in surveying reproduction in female amphibia discussed the role of exteroceptive factors such as rainfall and temperature in controlling pituitary activity via the hypothalamus. He described experiments on the relation between thyroid activity and the sympathetic system which might bear upon the possible participation of an adrenergic component in the functional pathway between the hypothalamus and
\end{abstract} the hypophysis.

Reptiles, which have been comparatively little studied by endocrinologists, were surveyed under four heads, Sauria, Ophidia, Crocodilia and Chelonia, by Dr. R. Kehl (Algiers) in a joint paper with $C$. Combescot. Much of the paper was taken up with a description of Dr. Kehl's own work on the Algerian saurians, Uromastix and Acanthodactylus, which is providing much needed additional information about this class. Dr. M. R. Miller (California), in the discussion, described Californian reptiles in which the male interstitial cells show no evidence of endocrine activity. The meeting entered upon less exotic ground with a stimulating survey by Dr. A. J. Marshall (London) of reproduction in male birds, which included some slides illustrating his own observations on the periodic apperance of cholesterol-positive lipids in the testes. His references to the work of K. G. Wingstrand and particularly that of J. Benoit and I. Assenmacher, which suggests that the gonadotrophic function of the pituitary in birds is stimulated by a chemotransmitter of neuro- secretory origin passing down the pituitary portal vessels, followed by an all-too-brief exposition by Prof. Benoit himself of his elegant experiments, aroused much interest. This prompted Prof. Zuckerman, who earlier as chairman had eschewed controversy by virtue of his office, to express scepticism as to the completeness of the experimental evidence for the involvement of the pituitary portal vessels in the hypothalamic control of pituitary function as postulated by Benoit for birds and by G. W. Harris for mammals. Reproduction in female birds was surveyed by Dr. W. R. Breneman (Indiana), who, in the course of his exposition, described cytological work carried out by his colleague, F. Payne, on the avian pituitary in various reproductive phases. Evidence that the avian ovary produces progesterone and androgen as well as cestrogen was presented. This paper gave rise to discussion on, among other topics, the mechanism which determines the number of eggs in a clutch. This is probably neurogenic, and it seems possible that it may be more or less analogous to the suckling stimulus in mammals which, if intense enough, can stop the ovarian cycles. This theory involves the idea that the brood spots of birds are homologous with the mammæ of mammals and so may be sensitive to prolactin, as may be the ventral glands in the Chinese swifts said to secrete the edible birds' nest cement, prized by gourmets as an ingredient of soup.

Prof. Zuckerman at this point exchanged the role of chairman for that of lecturer and, with characteristic scholarship, surveyed the mammals in a joint paper with P. Eckstein. His main thesis in reviewing the manifold reproductive patterns found in this class was that many of these variations may not be differences in kind so much as components of a continuous spectrum. In discussing this paper, Dr. S. J. Folley cited the domestic cow as a probable example of a form from which a primitive breeding season has been eliminated by selective breeding. This was followed by diverting exchanges between Prof. Zuckerman and Dr. Parkes, who pleaded for the simple view of natural phenomena. Dr. L. Harrison Matthews (London) then undertook a wide survey of reproductive processes in vertebrates in a paper the topic of which was the evolution of viviparity. The discussion on this paper was notable for an impressive and scholarly contribution by Prof. E. C. Amoroso in which, after considering the adaptations which viviparity has necessitated, he drew a penetrating parallel between the increasing complexity of the endocrine function of the placenta and the lengthening of pregnancy. The comparative survey was concluded by a paper by Dr. E. Witschi (Iowa) on vertebrate gonadotrophins which was mainly occupied by a consideration of results obtained with an assay technique based on plumage changes in the weaver finch. $\mathrm{H}_{\theta}$ concluded from his results that the luteinizing and interstitial-cell-stimulating hormones are separate and distinct pituitary hormones, a conclusion which, however, did not command the support of two of his compatriots, Drs. R. O. Greep and J. H. Leathem.

The third day of the symposium was occupied by papers on the effects of sex hormones in vertebrates. Dr. J. M. Dodd (St. Andrews) began with a survey of the position in fish and lower chordates, in the course of which it became evident that his results lead him to differ somewhat from the views of D. B. Carlisle on the endocrine function of the sub-neural gland in ascidians which some regard as a primitive 
pituitary. Dr. Carlisle intervened in the discussion to clarify his position. Dr. L. Gallien (Paris) described experiments on the effects of sex hormones on sexual differentiation of the larvæ of amphibia. It is possible to achieve total sex inversion in amphibians by administration of the appropriate (mammalian) sex hormone at an early enough stage, showing that the development of the gonocytes is controlled not by genes but by endocrine factors arising out of the competing influences of the gonadal cortex and medulla. Dr. R. M. Fraps (Beltsville), in dealing with birds, described interesting experiments on the mechanism of ovulation in the domestic hen which indicate that the secretion of ovulating gonadotrophin (LH) by the pituitary is called forth by a progestogen (progesterone itself?) secreted by the follicle next due to ovulate. The secretion of the progestational hormone is probably evoked by pituitary luteotrophin (prolactin). In the discussion on this paper Prof. Benoit described among other things the masculinizing effect of cortisone on ducks.

Dr. J. H. Leathem (Rutgers), to whom the paper on mammals was entrusted, discussed important species differences in the effects of steroids on the reproductive system of both male and female. Dr. T. Mann, commenting on this paper, illustrated this point by references to the marked differences between various species of mammal as regards the respective sites of origin of the fructose and citric acid found in the seminal plasma. Dr. A. Jost (Paris) concluded this part of the symposium with a paper describing his investigations on the effects of sex hormones on sexual differentiation in the foetus, which show that this is not a continuous process ; rather, there occurs a critical period of testicular activity during which the character of the sexual structures is determined for life. Experiments involving hypophysectomy by the rather drastic procedure of decapitation (which, incidentally, is not fatal to the foetus) indicate a gonadotrophic function for the foetal pituitary. His admiration for the elegance of Dr. Jost's experiments tempted the chairman into a gentle tilt against the chemists, who, however, found a champion in Dr. Folley. In a masterly summing-up of this part of the proceedings, Prof. Zuckerman referred to the unique character of the meeting thus far, so broad and all-embracing had been the field covered. He reminded his audience that despite the astonishing variety of the reproductive patterns encountered even within one class, the underlying mechanisms seem nevertheless basically the same all through. It was good to hear Prof. Zuckerman predict that endocrinology will soon emerge from the "ACTHcortisone era".

In opening the second part of the symposium, the chairman, Dr. Folley, referred to the evolution of devices for conserving water so as to preserve the aquatic environment necessary for the aqueous cell chemistry which is the basis of life. In considering the role of the endocrine system he mentioned recent achievements such as the discovery of aldosterone and the synthesis of the oxytocic polypeptide which can only serve to encourage further efforts in this field. The first paper, given by Prof. E. J. Conway (Dublin), began with a fundamental treatment of ionic equilibria in isolated muscle tissue before proceeding to consider the application of these principles in studies involving the adrenal cortex. It was interesting to learn that adrenal corticoids can influence ionic transport through the cell membrane of the yeast cell. Prof. H. Heller (Bristol) in a paper on mammals described the various physiological stimuli (dehydration, stimulation of vagal afferents, suckling, ete.) which cause secretion of the pressor-antidiuretic hormone. An old adage of the Hogben school, to the effect that when one measures hormone excretion in the urine one may be merely studying kidney physiology, came to mind in connexion with the mention of findings which suggest that the kidney may convert pressor-antidiuretic hormone into a less biologically active form prior to excretion. In comment upon a point raised by Prof. Heller's paper, Dr. Folley referred to the careful experiments of Mrs. M. H. I. Dodd at Shinfield which indicate that neither the lactating state itself nor the application of the milking stimulus has any detectable effect on the amounts of pressor-antidiuretic hormone and oxytocin in the posterior lobe of the goat. He also pointed out that evidence of differential secretion of the two posterior lobe principles has been provided by the work of $\mathrm{C}$. Peeters, of Ghent, who showed that suckling antidiuresis in water-loaded cows could be inhibited by mild fright, while the milk-ejection reflex (believed to involve oxytocin secretion) was not affected. An interesting contribution to the discussion came from Dr. F. G. Hofmann, who described a creature of the American desert, the kangaroo rat, which is geared to maximum water conservation and shows a great impediment to water excretion, yet its response to pressor-antidiuretic hormone is equal to that of the ordinary rat.

A paper on amphibia was read by Dr. W. H. Sawyer (New York). He emphasized the key position of this class which, situated as it is between water and dry land, may provide the best experimental medium for elucidating the basic principles of salt and water balance. Dr. Sawyer visualized the neurohypophysis as playing the primary part in regulating water balance and the adrenals as having precedence in regulating salt metabolism. He felt that, for amphibia as for mammals, the respective roles of the two glands are complementary rather than antagonistic as so often regarded. In the ensuing discussion, Dr. C. Barker Jørgensen described experiments, partly with $K$. G. Wingstrand, on section of the supraopticohypophysial tract in Rana temporaria which resulted in a decrease of neurosecretory material but did not affect the rate of water uptake. Then Dr. V. Capraro (Milan) read a joint paper with M. L. Garampi describing experiments on effects of posterior-pituitary extracts on the rate of water flow through the isolated frog skin which indicate that mechanisms more complicated than simple changes in pore size are involved. As pointed out by Prof. Pumphrey, such results are likely to depend to an important degree on the season in which the frogs are taken, since the winter frog is physiologically a very different creature from the summer frog.

In the final session the first paper was by Prof. M. Fontaine (Paris), who gave an excellent general survey of the endocrine control of water and salt metabolism in fish. He was followed by Dr. D. C. W. Smith (St. Andrews) with an admirable account of some of the interesting work in progress at the Gatty Marine Laboratory on the relation between the endocrines and salinity tolerance in Salmonidae. The thyroid hormone and pituitary somatotrophin seem to be of importance here. The last paper was given by Dr. $\mathrm{I}$. Chester Jones (Liverpool), who in refreshing style surveyed the role of the adrenal cortex in salt and water metabolism in vertebrates. In the dis- 
cussion, observations on water diuresis in patients with adrenal insufficiency were described by Dr. A. Slessor, while Dr. M. Ginsburg described experiments on the relation between the adrenals and the rate of disappearance of injected pressor-antidiuretic hormone from the blood in rats.

In the course of both parts of the symposium there were references from time to time to a dictum attributed to a distinguished zoologist not present at the meeting, to the effect that it is not the hormones themselves which evolve but rather the uses to which they are put. The chairman briefly returned to this concept in his final summing-up. He regarded it as inherently improbable and cited a number of facts which suggest that hormones are suitable material upon which the evolutionary process can work. This prompts the thought that if a sequel to this symposium is organized in a few years time-and in view of the evident success of the present one it is to be hoped that this will be the case-then perhaps a suitable theme will be "The Evolution of the Endocrine System".

If the above suggestion is acted upon, it would please many if the sequel were held under the same auspices, for the atmosphere of this symposium was extraordinarily pleasant and all the arrangements reflected great credit upon the originator and organizer, Dr. I. Chester Jones. This was acknowledged in a graceful speech at the end by Prof. Benoit, as was the pleasant hospitality accorded to the participants in functions arranged by the Merseyside Civic Society, the University of Liverpool and Prof. Pumphrey.

By arrangement with the Society for Endocrinology, the proceedings will be published as soon as possible in two volumes (Nos. 4 and 5) of the recently established series of Memoirs of that Society, the Royal Society having made a generous grant towards the expenses of publication.

S. J. Folley

\section{PHYSIOLOGY IN HUNGARY}

$\mathrm{T}$

HE twentieth (anniversary) annual conference of the Hungarian Physiological Society was held during July 8-10 in Budapest, under the presidency of Prof. Brunó Straub, and to mark the occasion the Hungarian National Academy of Sciences invited a number of guests from other countries to attend the meetings and to participate in the discussions. The programme, which contained 128 communications, demonstrated both the high quality of work in progress in the fields of physiology, biochemistry and pharmacology, and also the remarkable number and keenness of the younger generation of Hungarian scientific workers. Besides these papers, which were divided into three concurrent sections, there were plenary sessions, the first being devoted to a general report by Prof. $G$. Romhányi (University of Pécs) on the most recent discoveries relating to biological structure and function, and the others to lectures and communieations by the foreign visitors.

From neighbouring countries came, among others, the Polish biochemists and physiologists, W. Niemerko (now director of the Nencki Institute, soon to return from Lodz to new quarters in Warsaw) and W. Missiuro ; several Czechoslovak guests, including Dr. E. Gutmann (who at one time worked in Oxford) ; the Rumanian medical physiologists, Danielopulo and Julius Nitzulescu; and Prof. Gotséeff, of Bul- garia (one of the pupils of the late Sir Joseph Barcroft). The U.S.S.R. sent Prof. P. S. Kupalov (a former colleague in years gone by of Prof. A. V. Hill), Prof. S. C. Koschtojanz, the comparative physiologist, with the neurologists R. Kavetsky and A. Vorobyov. From the United Kingdom came the present writers, and from Germany the biophysicist Prof. Havermann (Berlin).

For more than twenty-five years, especially since the fundamental work of Szent-Györgyi and Straub in 1941 on the relations of actin and myosin, Hungarian physiology and biochemistry have been renowned for interest in the mechanism of muscular contraction. This was particularly in evidence at the present meetings, and for reasons of personal interest we shall report upon it a little more fully. Subjects which came under lively discussion included the effects of various extractants upon the appearance of muscle fibrils under the polarizing and electron microscopes; the early rapid phase of volume diminution accompanying the action current; the binding of metallic ions (especially $\mathrm{Ca}++$ and $\mathrm{Mg}^{++}$) by actin and myosin; and comparison of these proteins with others in this respect. The binding of $\mathrm{Ca}^{++}$by muscle mitochondria was also reported upon. Interesting discussions were evoked by new investigations of the bound nucleotides in muscle and other cells, not only by Hungarian workers but also by Niemerko from Poland. A further topic was the cholinesterase activity of the mero-myosins prepared by tryptic hydrolysis ; all of it was found to be in the $\mathrm{L}$-mero-myosin just as all the adenosine triphosphatase actuity is in the $\mathrm{H}$-meromyosin. Among the workers presenting these papers were, with their many collaborators, E. Ernst, F. Guba, T. Erdös, G. Feuer, E. Biró, M. Bárányi and E. Varga.

Dr. I. Banga described some recent developments of her work on elastin, particularly in relation to the dependence of its elasticity on provision of water. Since elastin itself cannot bind water, the presence in the neighbourhood of water-binding collagen is essential. Dr. Banga and her husband, Prof. Joseph Baló, who directs one of the institutes of pathology in the University of Budapest, are much concerned with problems such as those of arterio-sclerosis.

Prof. Straub, while maintaining his interest in actin, has turned his attention also to protein synthesis. Papers from his laboratory included those on penicillinase synthesis in $B$. cereus, and on amylase synthesis in pancreas homogenates, in the presence of adenosine triphosphate. Interesting effects of ions on glutamine synthesis were also reported.

At the conclusion of the conference, the foreign visitors, together with some of their Magyar hosts, made excursions to the provinces to see the Freshwater Biological Institute on the shores of Lake Balaton, and the Universities of Pécs and Debrecen. The Biological Station at Tihány, where in the past several British investigators have worked, is in good condition, and in many ways well equipped, especially with a fine library. Under the direction of Dr. Bela Entz and Mr. I. Konok, work is proceeding on the hydrobiology of the lake with reference to the fisheries, and on the comparative physiology of invertebrates, including insect hormones. There is space for about twenty workers, and the collecting facilities include a good motor-cruiser.

The University of Pécs was first founded in A.D. 1367; but ceased to exist when the great majority of its students were killed in resisting the 